\title{
Peran Pendidikan Ekonomi pada Pengrajin Dupa Ratus
}

\author{
Achmad Maulana Adyaksa $^{1}$, Hari Wahyono ${ }^{1}$, Cipto Wardoyo ${ }^{1}$ \\ ${ }^{1}$ Pendidikan Ekonomi-Universitas Negeri Malang
}

\begin{tabular}{l}
\hline \hline INFO ARTIKEL \\
\hline Riwayat Artikel: \\
Diterima: $18-11-2019$ \\
Disetujui: $14-05-2020$ \\
\hline
\end{tabular}

\section{Kata kunci:}

economic education; hundred incense craftsmen; informal education; non-formal education; pendidikan ekonomi; pengrajin dupa ratus; pendidikan informal; pendidikan nonformal

\begin{abstract}
ABSTRAK
Abstract: The hundred incense craftsmen in the village of Dalisodo initially had jobs as farmers and ranchers until finally they chose to become hundred craftsmen of incense. The existence of hundred incense craftsmen in the Dalisodo village is very influential on the development of the Dalisodo village especially in the Malang Regency because they are able to produce high quality products and the products are marketed all the way to Bali Island. The method of this research uses qualitative. With this type of approach to femenology. And in determining subjects using puposive sampling. In carrying out every activity, the hundred incense craftsmen possess the role of economic education, including from the family, craftsmen, laborers, and in the hundred incense production process.
\end{abstract}

\begin{abstract}
Abstrak: Pengrajin dupa ratus di Desa Dalisodo pada awalnya memiliki pekerjaan sebagai petani dan peternak hingga akhirnya mereka memilih menjadi pengrajin dupa ratus. Keberadaan pengrajin dupa ratus di desa Dalisodo sangat berpengaruh terhadap perkembangan di desa Dalisodo, khusunya di wilayah Kabupaten Malang karena mereka mampu memproduksi dengan produk yang sangat berkualitas dan hasil produksi di pasarkan hingga ke Pulau Bali. Metode penelitian ini menggunakan kualitatif dengan jenis pendekatan fenomenologi dan dalam menentukan subyek menggunakan puposive sampling. Di dalam melakukan setiap kegiatannya, pengrajin dupa ratus memiliki peran pendidikan ekonomi, meliputi dari dalam keluarga, pengrajin, buruh kerja, dan di dalam proses produksi dupa ratus.
\end{abstract}

\author{
Alamat Korespondensi: \\ Achmad Maulana Adyaksa \\ Pendidikan Ekonomi \\ Univesitas Negeri Malang \\ Jalan Semarang 5 Malang \\ E-mail: ach.maulana.adyaksa@gmail.com
}

UMKM mempunyai peran yang besar terhadap negara Indonesia. Salah satu peran UMKM adalah memperbanyak lapangan pekerjaan dan memperkecil angka kemiskinan. Sebagai salah satu upaya untuk mengatasi angka kemiskinan adalah dengan menyediakan lapangan pekerjaaan untuk masyarakat (Sukmana, 2018). Hal ini terbukti pada tahun 1997 saat Indonesia dilanda krisis moneter UMKM tetap eksis menjalani bisnisnya, selain itu UMKM berperan untuk mengurangi angka pengangguran. Jika tingkat kemiskinan tinggi berarti proses pembangunan ekonomi belum dapat menyejahterahkan masyarakat dengan merata (Andhykha, Handayani, \& Woyanti, 2018). Peranan UMKM sangatlah diperlukan untuk dapat memunculkan lapangan pekerjaan yang baru. Dengan adanya lapangan kerja baru diharapkan dapat mengurangi pengangguran yang ada (Syamyatmoko, 2017).

Kota Malang banyak mengembangkan berbagai macam industri, seperti industri pertanian, pariwisata, maupun perkebunan. Namun, tidak mengesampingkan adanya UMKM sebagai salah satu penopang perekonomian suatu daerah. Hal ini dibuktikan bahwa banyaknya kebijakan yang telah diberikan oleh pemerintah setempat guna memberdayakan UMKM yang ada. Terdapat data dari Dinas Koperasi bahwa setiap orang yang tergabung dalam kelompok ekonomi produktif, koperasi, dan UMKM diberikan penguatan modal untuk pengembangan melalui program pemerintah, seperti APBD Kabupaten dan lain sebagainya. Dengan demikian, diharapkan lembaga keuangan dapat memberikan pendampingan untuk penguatan modal dengan bunga rendah, seperti progam KUR sehingga dapat mendorong perkembangan UMKM (Irmawati, Damelia, \& Puspita, 2013). Desa Dalisodo adalah salah satu daerah yang UMKM nya berkembang pesat. Hal ini selain dibuktikan dari data pemerintahan pusat juga dibuktikan melalui observasi yang dilakukan peneliti pada saat di lapangan. Hasilnya Desa Dalisodo merupakan desa penyuplai dupa ratus yang sudah diminati oleh warga umat Hindu dan distributor besar di Bali. Hal ini menunjukkan kalau barang yang diproduksi UMKM tidaklah eksis di pasar daerah saja, namun dapat menembus ke pasar luar daerah, yaitu pasar nasional (Putra, 2016). Dari hasil wawancara dengan Kepala Desa Dalisodo didapatkan informasi bahwa sebagian besar warga di desa tersebut menjadi pengrajin dupa ratus, sebagian adalah pemilik dan sebagian adalah pekerjaanya. 
Melimpahnya bahan baku membuat masyarakat menekuni usaha ini. Dalam perkembangannya, peran UMKM harus memiliki ciri khas dan keunikan dalam setiap menciptakan produk hal itu merupakan strategi yang harus digunakan (Syukriah \& Hamdani, 2013). Bahan bakunya adalah bambu sebagai bitingan dupa dan serbuk kayu sebagai bahan campuran dupa. Namun, jika permintaan melonjak bahan baku juga didapat di luar Malang contohnya Trenggalek dan Ponorogo. Di Desa Dalisodo dapat menghasilkan tujuh ton dupa dan omzetnya per keseluruhan kelompok mencapai 300 juta dalam sebulan. Omzet ini akan bertambah jika memasuki Hari Raya Nyepi dan perayaan umat Hindu lainnya. Namun para pengrajin mengaku kuwalahan jika memasuki musim hujan karena ini menyebabkan dupa ratus tidak dapat kering dengan maksimal dan menjadikan dupa ratus tumbuh jamur. Untuk mengantisipasi hal tersebut, pengrajin memproduksi dupa lebih bayak di musim panas. Pengelolahan usaha harus disertai dengan adanya evaluasi dan analisa tentang kemampuan usaha tersebut sehingga dapat bersaing dan tetap berkembang di masa yang akan datang (Novitawati \& Fajarwati, 2018). Berdasarkan hasil observasi di awal, peneliti ingin mengulik informasi lebih dalam yang berkaitan dengan kegiatan pengrajin dupa ratus di Desa Dalisodo yang berkontribusi dengan pendidikan ekonomi.

\section{METODE}

Dalam penelitian ini, peneliti menggunakan metode kualitatif. Tujuan penggunaan metode kualitatif agar mendeskripsikan secara menyeluruh dan lengkap mengenai kegiatan pengrajin dupa ratus serta melakukan analisis mendalam tentang faktor-faktor yang memengaruhi pendapatan pengrajin dupa ratus di Desa Dalisodo. Untuk penjaringan data menggunakan metode snowball sampling atau teknik bola salju hal ini memiliki tujuan agar dapat menjamin kredibilitas data yang ditemukan. Dan teknik ini berhenti apabila ada kejenuhan data. Peneliti memilih lima orang pengrajin yang dijadikan sebagai informan. Prosedur pengumpulan data dilakukan dengan menggunakan metode (1) penelitian langsung di lapangan, (2) tanya jawab langsung dengan pengrajin, dan (3) pengambilan gambar untuk bukti penelitian. Untuk analisis datanya, meliputi (1) mengumpulkan data yang otentik, (2) pemilihan data atau mentrasformasi dari data asli yang didapat di lapangan untuk di tulis dihasil penelitian, (3) menyajikan setiap data ke dalam tulisan/hasil penelitian, dan (4) penyimpulan (verifikasi).

Dalam pengecekan keabsahan data menggunakan (1) kredibilitas, (2) transferbilitas, (3) ketergantungan pada konteks, dan (4) konfirmabilitas. Pengecekan keabsahan penelitian ini dikerjakan dengan peneliti sendiri, peneliti menggunakan dengan cara memperpanjang waktu penelitiannya.

\section{HASIL}

Berdasarkan hasil penelitian di lapangan, terdapat perbedaan dari informan satu dengan informan yang lainnya. Hal ini dapat dijelaskan pada tabel 1 .

Tabel 1. Peran Pendidikan Ekonomi Pada Pengrajin Dupa Ratus

\begin{tabular}{|c|c|c|c|}
\hline & \multicolumn{3}{|c|}{ Representasi Pendidikan Ekonomi } \\
\hline Informan & Pendidikan Ekonomi Informal & Pendidikan Ekonomi Nonformal & Peran Pendidikan Ekonomi \\
\hline 1 & $\begin{array}{l}\text { - Harus hidup mandiri } \\
\text { - Wajib bertanggung jawab } \\
\text { - Giat dalam melakukan pekerjaan }\end{array}$ & $\begin{array}{l}\text { - Pengalaman dan umur memengaruhi } \\
\text { kinerja para pekerja } \\
\text { - Pengalaman pekerjaan salah satunya di } \\
\text { dapat dari target yang diberikan }\end{array}$ & $\begin{array}{l}\text { - Membantu mengatur keuangan } \\
\text { - Membantu mengelola usaha dengan } \\
\text { benar }\end{array}$ \\
\hline 2 & $\begin{array}{l}\text { - Penggunaan sumber daya dengan } \\
\text { bijaksana } \\
\text { - Hidup harus bertanggung jawab } \\
\text { - Menanamkan sikap pantang menyerah }\end{array}$ & $\begin{array}{l}\text { - Dalam bekerja harus terampil dan } \\
\text { bertanggung jawab } \\
\text { - Harus ikhlas dalam melakukan pekerjaan } \\
\text { dan dalam memberikan pengertian kepada } \\
\text { pekerja } \\
\text {-Membuat peraturan di lingkup usaha agar } \\
\text { semuanya bersikap tertib }\end{array}$ & $\begin{array}{l}\text { - Membantu proses produksi serta } \\
\text { pemasaran dengan baik dan benar }\end{array}$ \\
\hline 3 & $\begin{array}{l}\text { - Mengajarkan pentingnya menabung } \\
\text { (menyisihkan uang) bagi semua latar } \\
\text { belakang } \\
\text { - Mengajarkan mulai hal terkecil }\end{array}$ & $\begin{array}{l}\text { - Pentingnya prinsip kebijaksanaan dalam } \\
\text { hal apapun dan disiplin dalam usaha } \\
\text { - Memberikan target dan tanggung jawab } \\
\text { kepada pekerja }\end{array}$ & $\begin{array}{l}\text { - Membantu pekerja agar tumbuh sikap } \\
\text { disiplin dan bertanggung jawab dalam } \\
\text { bekerja }\end{array}$ \\
\hline
\end{tabular}
contohnya: kejujuran dalam berusaha 
Tabel 1. Peran Pendidikan Ekonomi Pada Pengrajin Dupa Ratus (Lanjutan)

\begin{tabular}{llll}
\hline 4 & - Menanamkan sikap semangat dalam usaha & - Keahlian dan keterampilan & - Adanya pendidikan akan membuat pengelolaan \\
& - Mempercayakan kepada anak untuk & pekerja disesuaikan dengan & keuangan makin ribet akan tetapi diperlukan untuk \\
& mengolah uang dengan baik dan tetap & pekerjaannya & pengolahan produksi dupa \\
melakukan pendampingan & - Tidak menekan para pekerja & \\
& - Pemaparan tentang pentingnya mencatat & & \\
keuangan dalam dunia usaha & & - Pengelolaan keuangan tidak dibukukan sehingga \\
\hline 5 & - Menanamkan keberanian dalam & - Mengelola pengeluaran & uang masuk dan keluar tidak terkondisikan \\
& menjalankan suatu usaha & keuangan dengan benar & \\
& - Selalu mengikutkan keluarga dalam & - Menanamkan keseriusan dalam & \\
berdiskusi & bekerja & \\
\hline
\end{tabular}

Sumber: Data diolah oleh peneliti

\section{PEMBAHASAN}

\section{Potret Pendidikan Ekonomi pada Pengrajin Dupa Ratus di Desa Dalisodo}

Pendidikan ekonomi dari hasil penelitian terdapat dua ranah yaitu yang pertama terjadi dalam lingkup keluarga (informal) yaitu keluarga menjadi tempat pendidikan pertama untuk anak-anaknya. Lingkungan keluarga adalah lingkungan yang utama dalam membentuk karakter seorang anak (Karo-karo, 2014). Pendidikan ekonomi yang terjadi pada masyarakat di luar pendidikan formal (nonformal) hal ini terjadi di lingkungan usaha. Hal ini menjadi salah satu faktor tercapainya kesuksesan dalam berusaha. Pendidikan nonformal memiliki tujuan supaya masyarakat dapat terus mengembangkan potensinya (Soedarwo, 2017).

Dari hasil penelitian dalam pendidikan, keluarga adalah sosok yang sangatlah bersifat penting karena dapat memengaruhi berhasilnya suatu usaha. Untuk pengrajin pendidikan informal berfungsi untuk mewariskan budaya turun temurun dari generasi terdahulu menuju generasi yang sekarang (Darusman, Mumu, Mustakim, \& Herwina, 2019). Hal ini menunjukkan bahwa pendidikan informal adalah pendidikan warisan dari keluarga terdahulu seperti yang didapat dari kakek ataupun nenek. Hal ini disebabkan karena keluarga adalah interaksi terdekat dengan pertumbuhan seseorang. Setiap keluarga akan menerapkan pendidikan karakter karena dapat memengaruhi harapan setiap orangtua pada anaknya (Sukiyani \& Zamroni, 2014). Pendidikan keluarga adalah pendidikan dasar sebelum terjun ke masyarakat luar. Pendidikan keluarga juga mempunyai tujuan mengembangkan pola pikir, perilaku seseorang serta karakteristik orang. Oleh karena itu, dalam keluarga yang mengajarkan pendidikan ekonomi dengan benar akan menjadikan seorang anak yang mampu berpikir rasional dengan menggunakan prinsip ekonomi pada kegiatan sehari-hari. Di dalam keluarga sangatlah penting mengajarkan sikap yang benar sehingga anak ataupun keturunan kelak akan memiliki sikap efektif dan efisien ketika menjadi kepala keluarga (Fahmi, Wahjoedi, \& Widjaja, 2016). Selain itu, anak akan mampu mengolah keuangan dengan baik dan juga mampu mengolah sumber daya lainnya dengan baik pula hal ini dapat menjadikan anak bersikap mandiri dan penuh tanggung jawab untuk mencapai sebuah keberhasilan. Setiap proses pendidikan anak sebagaimana dapat terjadi di persekolahan, masyarakat maupun keluarga (Idrus, 2012).

Pemilik usaha yang juga berperan sebagai orangtua dengan modal berkeinginan dan kemampuan untuk mendidik keluarganya dalam hal ekonomi akan memengaruhi pengelolahan suatu industri yang nantinya akan berdampak pada keberhasilan yang berbeda untuk setiap pengrajin dupa ratus di Desa Dalisodo. Hal ini menunjukkan bahwa pendidikan ekonomi yang diberikan dalam satu keluarga sangat dibutuhkan (Putra, Wahyono, \& Wardoyo, 2016). Jadi, tidak hanya pendidikan teori saja yang diberikan, namun langsung ke tahapan praktik yang didapat dari pendidikan keluarga sebelumnya ataupun pendidikan yang ada di sekitar lingkungan tempat tinggal.

Pendidikan nonformal adalah pendidikan antara pemilik usaha dengan karyawan yamg berlangsung di tempat usaha. Para pekerja akan bertemu para pemilik usaha di setiap harinya. Pendidikan nonformal terjadi secara langsung tanpa adanya jadwal tertentu. Sebuah usaha akan memiliki hasil atau keuntungan yang baik jika karyawannya mempunyai latar belakang pendidikan yang baik juga. Untuk hal semacam ini sebagai pemilik usaha diharapkan memberikan cerminan karakter karena akan menentukan suatu kesuksesan usaha tersebut (Utomo, Cahyaningrum, \& Hasyim, 2019). Begitupun sebaliknya jika memiliki latar belakang kinerja pekerjanya yang kurang baik maka akan membuat keuntungan usaha kurang baik juga. Lewat pendidikan nonformal khususnya dibidang keterampilan dapat memberikan kontribusi positif untuk menurunkan angka kemiskinan (Tohani, 2011).

Latar belakang pendidikan ekonomi nonformal yang dimiliki pengrajin dupa ratus masih kurang baik. Hal ini jika dibiarkan akan berdampak lahirnya pengrajin yang sama dengan pengrajin sebelumnya. Upaya pedidikan nonformal adalah salah satu bentuk penanggulangan agar tidak terjadi hal semacam itu. Dengan mayoritas penduduk yang banyak dikategorikan sebagai usia produktif harus dapat dimanfaatkan untuk selalu berkarya dan terus berkiprah (Maryati, 2015). Sebuah usaha yang didalamnya ada para karyawan yang punya cara kerja bagus yang mampu bekerja degan disiplin, bijaksana, dan efisien akan berdampak baik juga terhadap keuntungan dan kemajuan suatu usaha. Dengan adanya pendidikan akan mendorong pertumbuhan ekonomi (Nugroho, 2016). 


\section{Peran Pendidikan Ekonomi pada Pengrajin Dupa Ratus di Desa Dalisodo}

Peran pendidikan ekonomi pada pengrajin dupa ratus di ranah keluarga memberikan pengetahuan akan disiplin ilmu sebagai pelaku ekonomi. Pendidikan keluarga sebagai wujud hasil proses pendidikan yang merupakan pembelajaran serta pembiasaan sebagai terciptanya lingkungan yang memengaruhi perilaku pengrajin. Dari hasil penelitian pendidikan informal terjadi antara pengrajin dengan anggota keluarga dimana pegrajin memiliki peran lain selain sebagai pengelolah dari usahanya, pengrajin berperan sebagai panutan, khususnya untuk anaknya yang masih dalam proses identifikasi dan keluarga adalah lingkungan paling awal yang dikenal dan paling dekat.

Dengan anak yang ikut terlibat dalam aktivitas usaha keluarga anak tumbuh menjadi baik, bagi pendidikan sikap dan moral, seperti kejujuran dan tanggung jawab. Dalam keluarga juga dibina dengan sifat yang lain, misalnya mengembangkan nilai rajin, disiplin, dan kreatif melalui contoh perilaku orangtuanya yang dilakukan saat pengolahan usaha. Hal ini nantinya akan menjadi modal untuk anaknya agar dapat melakukan usaha maupun kehidupan yang sukses. Jangan sampai pengrajin yang juga orangtua tidak memberikan pendidikan yang baik untuk anaknya. Minimnya pengertian seorang orangtua kepada anaknya sangat mencolok ketika orangtua disibukkan dengan hal yang lain menjadikan hilangnya kehangatan komunikasi antara orangtua dan juga anak (Septianita, Abdurrahmansyah, \& Fauzi, 2019).

Begitu juga pendidikan di ranah nonformal berpengaruh terhadap kinerja suatu industri. Penerapan pendidikan ekonomi di Desa Dalisodo masih kurang karena masih membedakan antara juragan (pemilik usaha) dengan bawahan (pekerja). Seharusnya hal itu berjalan selaras guna untuk meningkatkan kemampuan para pekerja. Maka dapat diketahui kebutuhan pendidikan nonformal di masyarakat semakin meningkat guna mengembangkan usaha untuk menjadi lebih baik. Sangat diharapkan meningkatnya kualitas sumber daya manusia, contohnya yang ulet, disiplin, produktif, dan kreatif karena hal ini untuk melahirkan usaha-usaha yang berkembang (Murniawaty \& Murwatiningsih, 2018).

Hasil penelitian pada pengrajin dupa ratus di Desa Dalisodo baik pemilik maupun karyawan menunjukkan bahwa banyak masyarakat yang minim pendidikan formal atau tidak melanjutkan pendidikan ke jenjang selanjutnya, hal ini disebabkan karena berbagai faktor, salah satunya ialah keadaan ekonomi orangtua. Hal ini menjadikan pendidikan nonformal menjadi alternatif untuk layanan pendidikan terhadap mereka dan harus tercipta pendidikan yang sesuai dengan kebutuhan mereka.

Kejadian di lapangan membuktikan bahwa sangat penting adanya pendidikan ekonomi baik pada segi informal maupun nonformal bagi setiap orang. Pendidikan dapat meningkatkan kemampuan kinerja, kebijakan, dan keterampilan tak lupa agar mudah dalam menghadapi permasalahan yang timbul di sekitar kita. Dengan demikian, pendidikan inilah yang menjadikan seseorang bertahan dalam menghadapi persaingan industri.

\section{SIMPULAN}

Dalam lingkungan pengrajin dupa ratus di Desa Dalisodo tidak semua berpendidikan tinggi sehingga sumber daya manusianya tergolong rendah. Kurangnya pemahaman akan pentinganya pendidikan ekonomi membuat kurangnya penerapan pendidikan ekonomi dalam kegiatan produksi industrinya. Pendidikan ekonomi pengrajin dupa ratus di Desa Dalisodo terjadi pada pendidikan informal keluarga. Pendidikan ini terjadi antara pelaku usaha sebagai orangtua dengan anggota keluarganya, sehingga terjadi turun-temurun mengenai kebiasaan, proses produksi, pengelolahan usaha serta pendapatan dari kerajinan dupa ratus ini. Pendidikan yang diterapkan oleh masing-masing pengrajin berbeda-beda. Hal ini terlihat dari pencapaian kesuksesannya. Penerapan pendidikan ekonomi tidak sepenuhnya terlihat dalam proses kerajinan dupa ratus di Desa Dalisodo dan dapat dilihat dari kurangnya perhatian terhadap pembukuan keuangan. Maka nilai keuntungan bagi pengrajin berarti tidak adanya kerugian, hal ini kurang sesuai dengan pendidikan ekonomi bahwa suatu usaha atau kegiatan harus memperhitungkan segala aspek pengeluarannya tidak terkecuali tenaga dan proses pengerjaan serta bahan baku yang dipersiapkan.

Diharapkan bagi para pengrajin yang belum menerapkan pendidikan ekonomi untuk mau menjadi perantara terbentuknya lingkungan pengrajin dupa ratus yang menjadi lingkungan pembelajaran karena hal itu akan memberikan manfaat untuk para pengrajin dupa ratus yang lain. Bagi pengolah UMKM Kabupaten Malang agar lebih memperhatikan pendidikan ekonomi dalam industri kerajinan sehingga akan berpengaruh terhadap pengolahan industri yang menuju ke arah yang tambah baik dari sebelumnya. Untuk hasil penelitian yang telah dilakukan semoga dapat dijadikan bahan rujukan, sebagai informasi, dan bahan referensi penelitian selanjutnya agar nantinya proses ekonomi menjadi baik untuk dipraktikan di lingkungan pengrajin dupa ratus di Desa Dalisodo.

\section{DAFTAR RUJUKAN}

Andhykha, R., Handayani, H. R., \& Woyanti, N. (2018). Analisis Pengaruh PDRB, Tingkat Pengangguran, dan IPM terhadap Tingkat Kemiskinan di Provinsi Jawa Tengah. Media Ekonomi dan Manajemen, 33(2), 113-123. https://doi.org/10.24856/mem.v33i2.671

Darusman, Y., Mumu, M., Mustakim, M., \& Herwina, W. (2019). Model Pewarisan Budaya melalui Pendidikan Informal (Pendidikan Tradisional) pada Masyarakat Pengrajin Kayu. Wacana Akademika: Majalah Ilmiah Kependidikan, 3(1), 95108.

Fahmi, M. F., Wahjoedi, W., \& Widjaja, S. U. M. (2016). Konsep Pendidikan Ekonomi di Lingkungan Keluarga. National Conference on Economic Education. 
Idrus, M. (2012). Pendidikan Karakter pada Keluarga Jawa. Jurnal Pendidikan Karakter, 2(2), 118-130.

Irmawati, S., Damelia, D., \& Puspita, D. W. (2013). Dampak Sedimentasi Bendungan Soediman terhadap Sosial Ekonomi Masyarakat. JEJAK Journal of Economics and Policy, 6(2), 103-213. https://doi.org/10.15294/jejak.v7i1.3596

Karo-karo, D. (2014). Membangun Karakter Anak dengan Mensinergikan Pendidikan Informal dengan Pendidikan Formal. Elementary School JournaL PGSD FIP Unimed, 1(2).

Maryati, S. (2015). Dinamika pengangguran terdidik: tantangan menuju bonus demografi di Indonesia. Economica: Jurnal Program Studi Pendidikan Ekonomi STKIP PGRI Sumatera Barat, 3(2), 124-136.

Murniawaty, I., \& Murwatiningsih, M. (2018). Internalisasi Pendidikan Ekonomi Kreatif sebagai Bridging Course Pembelajaran Kewirausahaan. Equilibria Pendidikan: Jurnal Ilmiah Pendidikan Ekonomi, 2(1), 1-10.

Novitawati, R. A. D., \& Fajarwati, Y. E. (2018). Analisa UMKM di bidang pertanian di Desa Pandansari Kec. Ngantang, Kab. Malang (dengan pendekatan IE Matrix). Referensi: Jurnal Ilmu Manajemen dan Akuntansi, 6(1), 1-10.

Nugroho, S. B. M. (2016). Pengaruh Pendidikan terhadap Pertumbuhan Ekonomi. Media Ekonomi dan Manajemen, 29(2).

Putra, A. H. (2016). Peran UMKM dalam Pembangunan dan Kesejahteraan Masyarakat Kabupaten Blora. Jurnal Analisa Sosiologi, 5(2).

Putra, N. A., Wahyono, H., \& Wardoyo, C. (2016). Internalisasi Nilai-Nilai Pendidikan. Jurnal Pendidikan: Teori, Penelitian, dan Pengembangan, l(11), 2189-2193.

Septianita, G., Abdurrahmansyah, A., \& Fauzi, M. (2019). Peran Pendidikan In-formal dalam Mendidik Anak pada Keluarga Broken Home di Kelurahan Bukit Lama Kota Palembang. Jurnal PAI Raden Fatah, 1(1), 47-61.

Soedarwo, V. S. D. (2017). Pemberdayaan Masyarakat melalui Pendidikan Nonformal Berbasis Potensi Lokal dalam Membangun Desa Wisata Adat. Jurnal Sosiologi Pendidikan Humanis, 2(2), 96-102.

Sukiyani, F., \& Zamroni. (2014). Pendidikan Karakter dalam Lingkungan Keluarga. Socia: Jurnal Ilmu Ilmu Sosial, 11(1), 1-20. https://doi.org/10.21831/socia.v11i1.5290

Sukmana, O. (2018). Strategi Percepatan Pertumbuhan Lapangan Kerja dan Pengentasan Kemiskinan melalui Kebijakan Pengembangan Pariwisata. Sosio Informa, 4(3), 488-500. https://doi.org/10.33007/inf.v4i3.1570

Syamyatmoko, S. (2017). Fundamental Kewirausahaan Sebagai Media Penciptaan Lapangan Kerja di Bidang Fotografi. REKAM: Jurnal Fotografi, Televisi, dan Animasi, 12(2), 119. https://doi.org/10.24821/rekam.v12i2.1429

Syukriah, A., \& Hamdani, I. (2013). Peningkatan Eksistensi UMKM melalui Comparative Advantage dalam Rangka Menghadapi MEA 2015 di Temanggung. Economics Development Analysis Journal, 2(2).

Tohani, E. (2011). Pendidikan Nonformal dan Pengurangan Kemiskinan di Pedesaan. Walisongo: Jurnal Penelitian Sosial Keagamaan, 19(2), 385. https://doi.org/10.21580/ws.2011.19.2.163

Utomo, M. N., Cahyaningrum, W., \& Hasyim, B. (2019). Karakteristik Entrepreneur dan Kesuksesan Bisnis UMKM di Kota Tarakan. Jurnal Borneo Humaniora, 2(1), 1-7. 